\title{
The Off-Design Performance Simulation of Marine Gas Turbine Based on Optimum Scheduling of Variable Stator Vanes
}

\author{
Zhitao Wang, Jian Li, Kuo Fan, and Shuying Li \\ College of Power and Energy Engineering, Harbin Engineering University, Harbin 150001, China \\ Correspondence should be addressed to Zhitao Wang; wangzhitao@hrbeu.edu.cn
}

Received 12 March 2017; Revised 11 June 2017; Accepted 20 June 2017; Published 23 August 2017

Academic Editor: Nicolas Gourdain

Copyright (C) 2017 Zhitao Wang et al. This is an open access article distributed under the Creative Commons Attribution License, which permits unrestricted use, distribution, and reproduction in any medium, provided the original work is properly cited.

\begin{abstract}
As one of the antisurge techniques, the adjusting scheme of VSV under off-design conditions has a significant impact on the performance of gas turbines. In this paper, the one-dimensional characteristic of the compressor calculation program is embedded into the zero-dimensional overall gas turbine model, which replaces the original compressor characteristic module. Based on the assembling relationship of the actual components of the marine gas turbine, the architecture of the modular model library is designed, and an integrated simulation platform of marine gas turbine is developed by using MATLAB/GUI software. The influence of the first 3 rows of variable stator vanes of the 9-stage axial compressor working alone on the performance of the compressor at different speeds and different angles was analyzed by the HARIKA compressor characteristic calculation program. Taking the economics and stability of the gas turbine as the optimization objective, the optimization of the first three-stage stator vanes regulation schemes under different working conditions was carried out. The steady-state performance parameters under each working condition of gas turbine of power generation with or without variable stator vane mode were calculated. The study results can provide references for the adjusting scheme of VSV under gas turbine off-design conditions operating process.
\end{abstract}

\section{Introduction}

As an important part of the gas turbine, the compressor should have high performance and enough margin and have higher efficiency [1]. Under the off-design condition, to avoid entering the unstable working state and ensure enough operating performance requirements, the variable-geometry compressor technology has become the mainstream. The matching and regulation of the variable-geometry compressor will directly determine the working performance of the gas turbine. In order to improve the operating efficiency of the gas turbine and to improve the matching relationship between the compressor and the gas turbine, how to adjust the stator blade angle will become a problem that researchers need to face. Compared with the experimental method to determine the regulation scheme of adjustable stationary blades, using the simulation method not only can save a lot of manpower and material resources but also can determine a reasonable adjustable stationary blades adjustment scheme in a short time.
Today, gas turbines are developing in the direction of complexity, scale, and diversification. The simulation process of a gas turbine becomes more complex [2]. Many researchers at home and abroad have carried out research in this area. In the late 1990s, National Aeronautics and Space Administration (NASA), united airlines industries, universities, and government institutions proposed the Numerical Propulsion System Simulation (NPSS) platform. This platform, using the simulation algorithm and the discipline coupling technology which can freely zoom and change dimensions, deeply reveals the complex flow inside the combustion engine and the mutual relations among the components and realizes the detailed simulation of the whole machine $[3,4]$. Simulation flow chart of high precision component modeling based on NPSS framework is shown in Figure 1. NPSS mainly contains five key technologies: (1) standard data interface; (2) using a flexible, modular, object-oriented program structure; (3) simulation and analysis of the specific physical process of the aeroengine according to the needs of the specific physical process; (4) multidisciplinary integrated technology; 

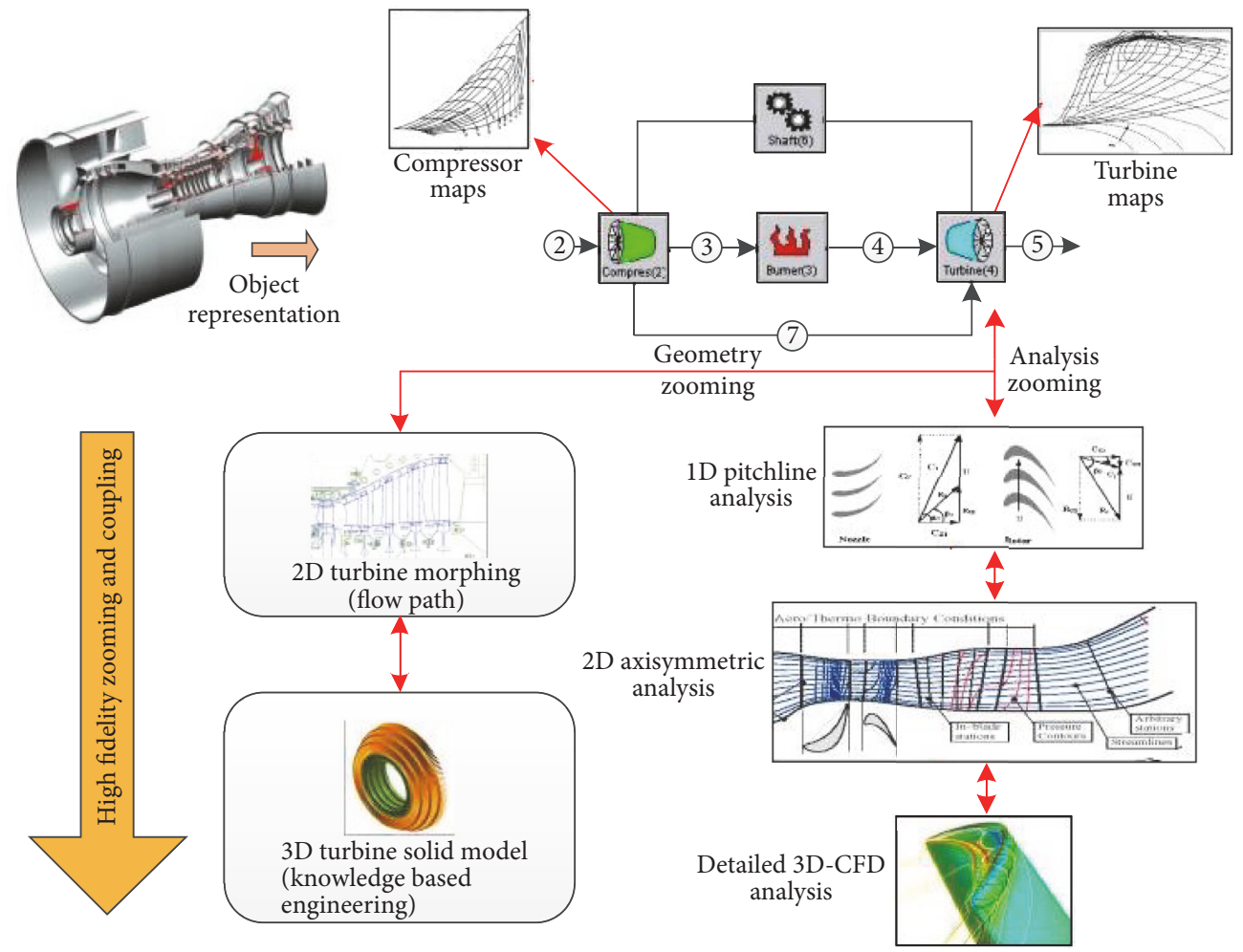

FIGURE 1: Simulation flow chart of high precision component modeling based on the NPSS framework [5].

and (5) high performance parallel and distributed computing technology [5].

The Russian Central Aero-Engine Research Institute (CIAM) developed the Computer Gas Turbine Engine Simulator (CGTES) to support the CT3 (Turbine Engine Test Technology) program [6]. CGTES is an independent computing system designed for the development of aeroengines. The simulation system can calculate the steady-state and transient-state parameters. The normal operation of the program is controlled by the special task input system. However, the precision of this kind of simulation technology is mainly affected by the establishment of a loss model and the selection of an empirical coefficient.

The off-design performance of marine gas turbines has great significance for the economy and stability of ships. As one of the surge-preventing measures of the compressor, variable stator vane (VSV) can be used to change the installation angle of the cascade with the working conditions changing to improve the compressor performance in the off-design conditions [7-11].

VSV technology has a long history and has been used in various applications of gas turbines. In the early 1940s, Germany's first turbojet engine Jumo004 applied the technology of VSV [12]. Figure 2 shows the stage numbers of VSV and the total stage numbers in several generations of aeroengine compressors.

In the field of ground power generation and marine gas turbines, VSV technology is also widely used $[13,14]$.

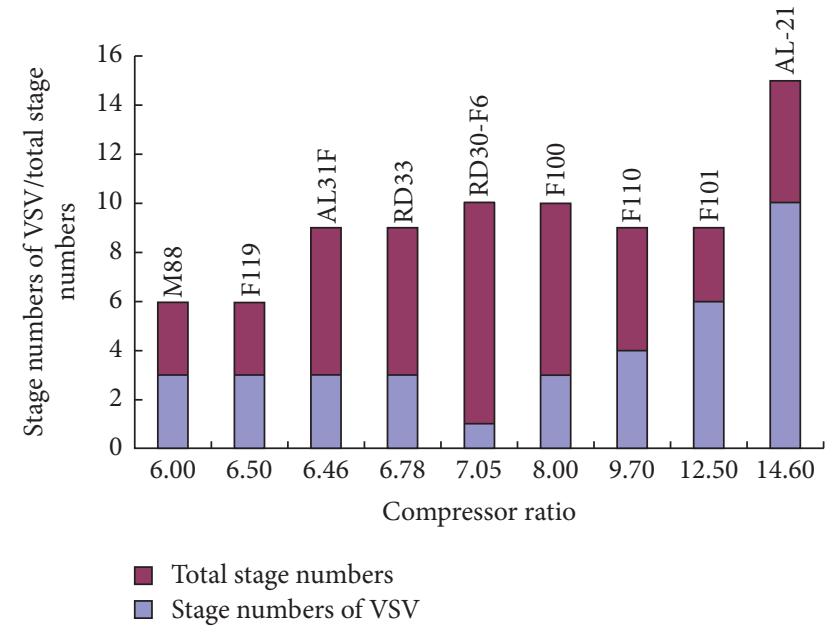

FIGURE 2: Stage numbers of VSV in the compressor [12].

US GE company's productions, 9FA-type gas turbine and PG6541-type single-axis gas turbine, both use inlet guide vanes, while the Swiss Sulzer company uses VSV technology in its AV series axial compressor. As a typical case in marine gas turbines, LM2500 gas turbine's top seven stages of its inlet guide vane and 16-stage stator blades are variable stator vanes $[15,16]$. Hu et al. established a method for calculating the characteristics of a multistage axial-flow compressor based on the inclusion of axial-flow 
compressor flow loss and lag angle model combining stepwise primitive blade model [17-20]. And based on the genetic evolutionary algorithm of the tournament, a two-objective genetic optimization algorithm is obtained. Zhang and Ren studied the influence of the adjustment of VSV on the compressor performance through the method of experiment. In order to improve the stage matching relationship and improve the performance of the compressor, an experimental procedure of adjusting the installation angle is introduced [21].

Through the review of the research status, we can know that the current research on VSV mainly focuses on the effect of VSV on compressor performance. The research on the influence of VSV on the performance of the whole gas turbine is relatively scarce. The research on the adjustment regulation of VSV mainly focuses on the performance of the compressor, and the research on the performance of the whole gas turbine is relatively less. Under the background of gas turbine integrated simulation, the method of simulating research on a certain part of the gas turbine from different perspectives is gradually mature by using the integrated modeling resources. Aiming at the problem mentioned above, this paper takes one three-shaft marine gas turbine for generation as the research object, adopts the modular modeling idea, establishes the general simulation model of (0-1D) variable dimension gas turbine considering a variable-geometry compressor, and optimizes the adjustment scheme of the top three stages of the variable stator vanes of the low-pressure compressor, and the influence of the variable stator vanes on the steady-state performance of the gas turbine was studied emphatically. The main contents of this paper are as follows.

Design an integrated simulation platform for marine gas turbines and build a simulation model library including a compressor, combustion chamber, turbine, rotor, and volume. According to the characteristics of the variablegeometry compressor, build the new compressor characteristics modules and interface modules.

A variable dimension turbine simulation model considering the variable-geometry compressor is established.

From the angle of the performance of the whole gas turbine, taking the top three grades of the variable stator vanes of the low-pressure compressor as the optimization variable, the economic efficiency and stability of the gas turbine under various working conditions are optimized. The results show that the optimized variable stator vane adjustment scheme can improve the performance of the gas turbine.

\section{Methodology}

2.1. Collaborative Running Interface Module. As the core part of the variable-geometry compressor model, the compressor interface module is the key to ensure the data transfer between the zero-dimensional models and one-dimensional characteristic calculation program. The whole interface module was built by S-function/MATLAB. The function of the compressor interface module mainly contains two parts: (1) to call the one-dimensional compressor performance calculation program and (2) to complete the update and data transfer of one-dimensional computing program's input files and output files.

The process of collaborative running is shown in Figure 3. When the simulation begins, the rotating speed and pressure ratio of the compressor can be obtained through the rotor module and the volume module. The flow coefficient and static blade opening adjustment value will also be given.

When Simulink is working, it first enters the simulation initialization phase. In this phase, the solver determines all the parameters of the module through the callback function and passes the signal width, data type, and state number. Meanwhile, the execution order, initial value, and the sampling time of each module are also determined.

Finally, other tasks in the initialization phase are performed before the simulation cycle phase. After entering the simulation cycle, the Simulink solver calculates the output of each module according to the predetermined order and uses the callback function to calculate the module status in the current sampling time, update the discrete state value, and calculate the differential value and the output value of the corresponding module.

After the simulation cycle phase, the Simulink solver calls the callback function to release the system storage space and performs other tasks that need to be done after the simulation step is completed.

The input files of HARIKA include the following: import conditions of variable-geometry compressors (i.e., import total pressure, import total temperature, and import airflow angle), relative speed, the main geometric size at all levels, and parameters such as the opening of variable static blade.

The output file mainly involves the compressor characteristic parameters including pressure ratio, flow rate, speed, and efficiency, which are calculated by the calculation program of compressor characteristics.

\subsection{Mathematical Model of Marine Gas Turbine with Variable-Geometry Compressor}

2.2.1. 1D Variable-Geometry Compressor Characteristic Model. When multiple variable stator vane angles change, the characteristics of the compressor will be changed in different angles. So, using only the zero-dimensional simulation cannot meet the need of modeling. One-dimensional simulation is mainly related to the component loss model, backward angle model of rotating parts, and some empirical coefficients. Therefore, the one-dimensional compressor performance calculation program can accurately reflect the variable-geometry compressor characteristics.

In this paper, HARIKA algorithm was used to calculate the one-dimensional compressor characteristic. Based on a large number of test data, HARIKA algorithm uses the statistical relationship of the stage synthesis characteristics to determine the stage parameters under off-design condition. The algorithm has been empirically modified along the vane height, and it has been empirically modified for various characteristic parameters of vane type as well. After obtaining the total pressure ratio and efficiency of one stage of the compressor, the velocity triangle at the outlet of this stage is further obtained. Using the velocity triangle as the inlet 


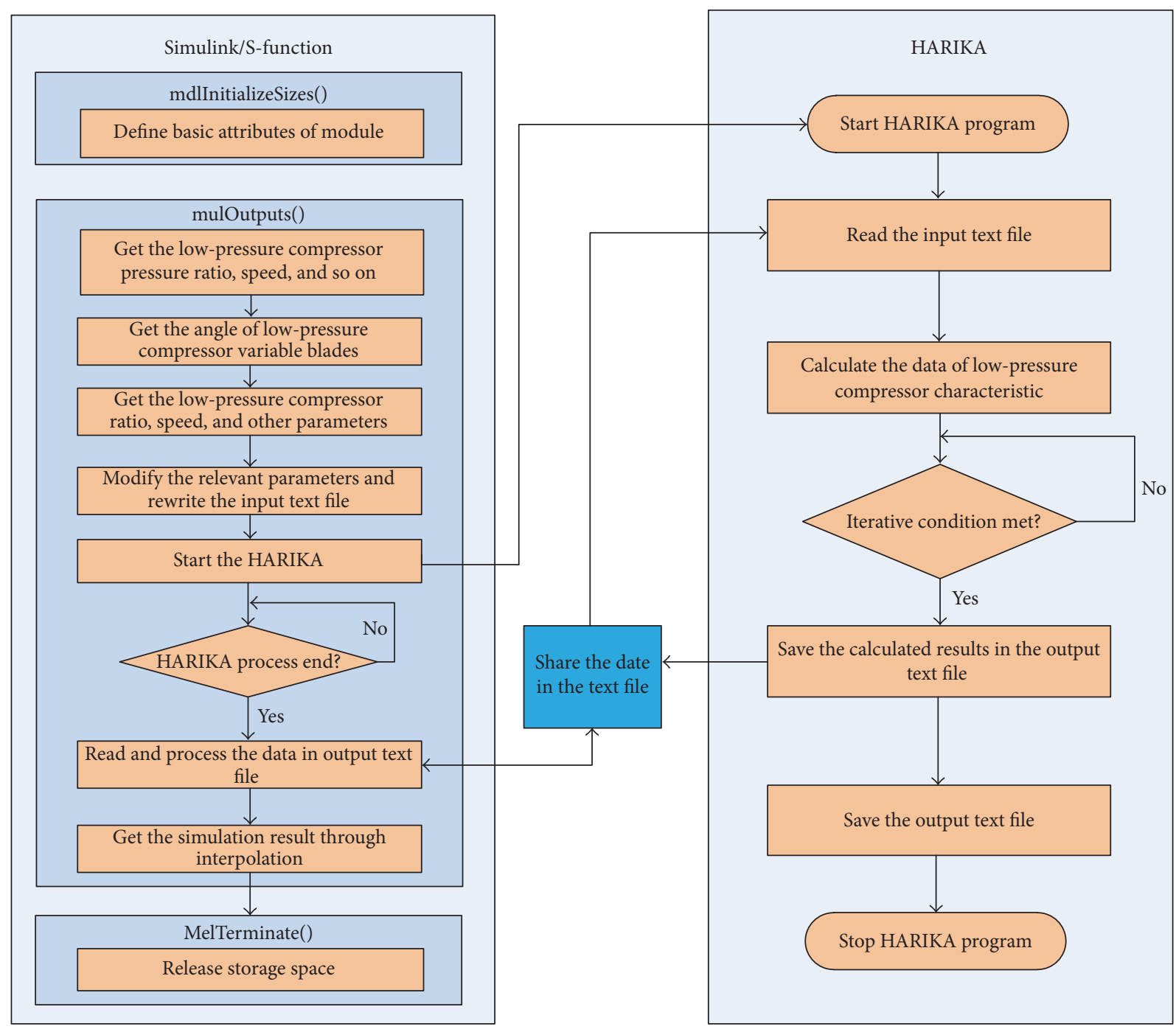

FIGURE 3: The process of collaborative running.

parameter of the next stage of the compressor, the parameters at the outlet of the next stage are obtained by the same method. The characteristics of the whole compressor can be obtained by repeating the process. The algorithm is more suitable as the calculation program of the characteristics of variable-geometry compressor components.

Figure 4 shows the compressor characteristics of experiment and calculation. The results show that the maximum error of the experiment and calculation is $4.8 \%$.

2.2.2. Compressor Performance Calculation. According to the compressor inlet temperature and compressor pressure ratio, we can determine the logarithmic ratio of the compressor outlet. Then, we determine the compressor exit enthalpy, and we can calculate the outlet temperature and compressor power.

The specific calculation process is as follows:

$$
\begin{aligned}
h_{\text {in }} & =f\left(T_{\text {in }}\right) \\
\lg \pi_{\text {in }} & =f\left(T_{\text {in }}\right)
\end{aligned}
$$

$$
\begin{aligned}
\lg \pi_{\text {out } a} & =\lg \pi_{\text {in }}+\lg \pi_{c} \\
T_{\text {outs }} & =f\left(\lg \pi_{\text {out } a}, T_{\text {in }}\right) \\
h_{\text {outs }} & =f\left(\lg \pi_{\text {out } a}, T_{\text {in }}\right) \\
\eta_{c} & =\frac{h_{\text {outs }}-h_{\text {in }}}{h_{\text {out }}-h_{\text {in }}} \\
h_{\text {out }} & =\frac{h_{\text {outs }}-h_{\text {in }}}{\eta_{c}}+h_{\text {in }} \\
T_{\text {out }} & =f\left(h_{\text {out } a}\right) \\
N_{c} & =G_{\text {in }}\left(h_{\text {out }}-h_{\text {in }}\right) .
\end{aligned}
$$

2.2.3. Combustion Chamber Model. During the process of establishing the model of combustion, we always consider the combustion chamber as a uniform field. 


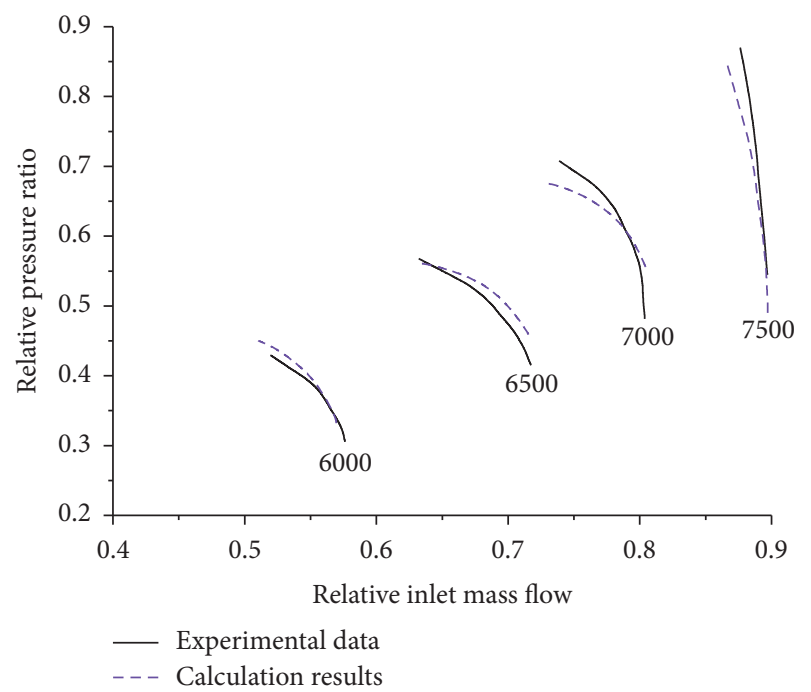

FIgURE 4: The compressor characteristics of experiment and calculation.

$$
\begin{aligned}
& \frac{d P_{b \text { out }}}{d t}=\frac{R_{g} T_{b \text { out }}\left(G_{b \text { in }}+G_{f}-G_{b \text { out }}\right)}{V_{b}}+\frac{P_{b \text { out }}}{T_{b \text { out }}} \frac{d T_{b \text { out }}}{d t} \\
& =\frac{R_{g} T_{b \text { out }}\left[k\left(G_{b \text { in }} h_{b \text { in }}+G_{f} H_{u} \eta_{B}-G_{b \text { out }} h_{b \text { out }}\right)\right]}{P_{b \text { out }} V_{b} C_{p}} \\
& \quad-\frac{R_{g} T_{b \text { out }} h_{b \text { out }}\left(G_{b \text { in }}+G_{f}-G_{b \text { out }}\right)}{P_{b \text { out }} V_{b} C_{p}},
\end{aligned}
$$

$P_{b o u t}$ for the outlet of the combustion chamber pressure and $T_{b \text { in }}$ and $T_{b \text { out }}$ for inlet and outlet temperature of the combustion chamber; $G_{b \text { in }}, G_{b o u t}$, and $G_{f}$ are the flow at the inlet and outlet of the combustion chamber and fuel injection quantity; $V_{b}$ and $k$ are the combustion chamber volume and index adiabatic of combustion chamber; $h_{b \text { in }}$ and $h_{b \text { out }}$ are the specific enthalpy at the inlet and outlet of the combustion chamber; $H_{u}$ is the low calorific value of fuel; $C_{p}$ is specific heat capacity at constant pressure of the combustion chamber volume.

2.2.4. Turbine Model. The turbine module is similar to the compressor module, and the mathematical model is as follows:

$$
\begin{aligned}
& \overline{n_{t}}=\frac{n_{t}}{\sqrt{T_{\text {tin }}}} \\
& \pi_{t}=\frac{P_{\text {tin }}}{P_{\text {tout }}} \\
& \overline{G_{t}}=f\left(\pi_{t}, \overline{n_{t}}\right) \\
& \eta_{t}=f\left(\pi_{t}, \overline{n_{t}}\right),
\end{aligned}
$$

where $T_{t \text { in }}$ is the turbine inlet temperature; $P_{\text {tin }}$ and $P_{\text {tout }}$ are the inlet and outlet turbo pressure; $\overline{n_{t}}$ is the turbine

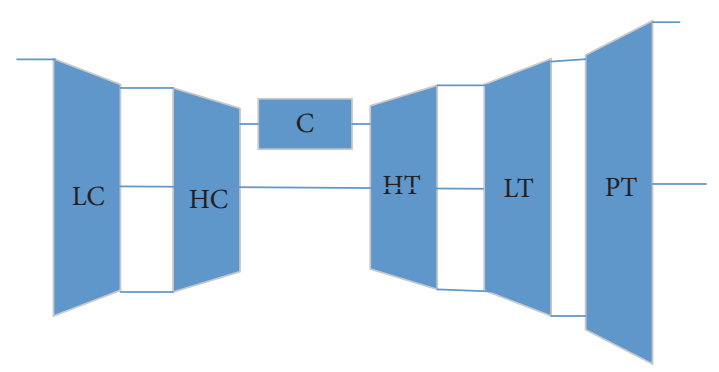

FIgURe 5: Physical model of the triaxial gas turbine.

corrected speed; $n_{t}$ is the turbine rotor speed; $\pi_{t}$ is the ratio of turbine expansion; $\overline{G_{t}}$ is the turbine corrected mass flow; $\eta_{t}$ is turbine efficiency.

2.2.5. Rotor Model. From the moment of momentum theorem, the product of the angular velocity of the rotor and the moment of inertia is equal to all the external torque on the rotor.

$$
\begin{aligned}
J \frac{d \omega}{d t} & =M_{T}-M_{C}-M_{m}-M_{L} \\
\omega & =\frac{2 \pi n}{60}, \\
N & =M \omega \\
\frac{d n}{d t} & =\frac{900}{J \pi^{2} n}\left(N_{T}-N_{C}-N_{m}-N_{L}\right),
\end{aligned}
$$

where $J$ is the rotor inertia; $M_{T}$ is the turbine torque; $M_{C}$ is the compressor torque; $M_{m}$ is the mechanical loss torque; $M_{L}$ is the load torque; $N_{T}$ is the turbine power; $N_{C}$ is the power consumption of the compressor; $N_{m}$ is the mechanical loss power; $N_{L}$ is the power loss load.

2.2.6. Volume Module Model. With the connection of the main components of the gas turbine, the flow space of the volume module can be regarded as global. In the volume, the flow rate of the working fluid is fast and the retention time is short, so we assume that the medium of heat transfer and import and export pressure is zero and assume central pressure instead of the average pressure of the working fluid inside the volume. According to the principle of conservation of mass, there is the following relationship:

$$
\frac{d P_{v}}{d t}=\frac{R_{g} T_{v \text { in }}}{V_{v}}\left(G_{v \text { in }}-G_{v \text { out }}\right),
$$

where $T_{v i n}$ is the volume of inlet temperature; $P_{v}$ is the volume internal average pressure; $G_{v \text { in }}$ and $G_{v \text { out }}$ are the import and export flows of volume.

\section{Application, Results, and Analysis}

This paper takes the triaxial gas turbine of a certain type as the physical model (as it is shown in Figure 5). Performance 


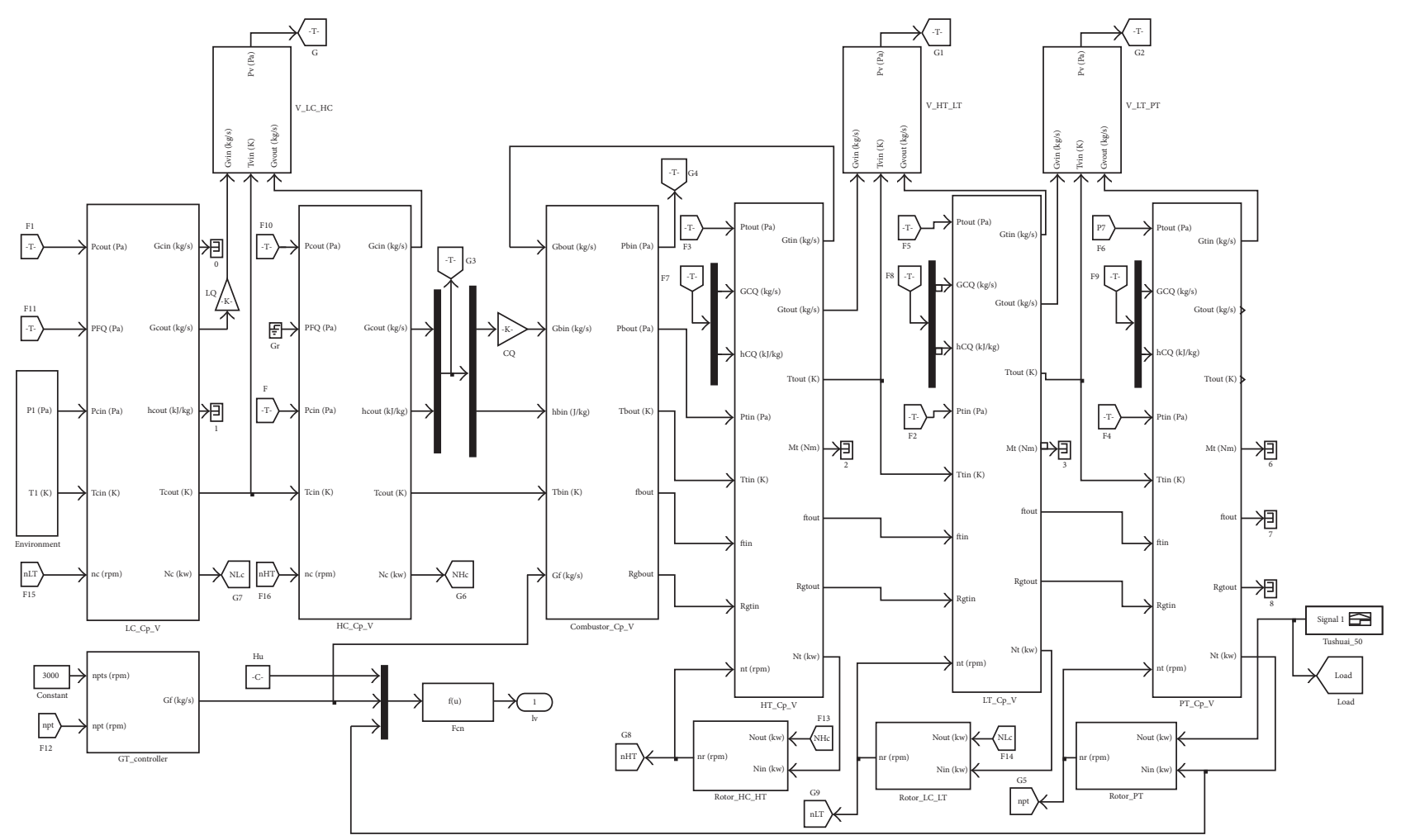

FIgURE 6: The simulation model of the gas turbine.

TABLE 1: Performance specifications of the gas turbine at standard sea level static ISA condition.

\begin{tabular}{lc}
\hline Air mass flow rate $(\mathrm{kg} / \mathrm{s})$ & 82 \\
Fuel flow rate $(\mathrm{kg} / \mathrm{s})$ & 1.62 \\
Turbine entry temperature $(\mathrm{K})$ & 1542 \\
Thermal efficiency $(\%)$ & 34.94 \\
Ambient pressure $(\mathrm{kPa})$ & 101.325 \\
Ambient temperature $(\mathrm{K})$ & 288 \\
\hline
\end{tabular}

specifications of the gas turbine at standard sea level static ISA condition is shown in Table 1. The comparison results of the various parameters of the gas turbine engine used in the marine power generation are shown in Figures 12-15 and Table 3.

3.1. The Gas Turbine Simulation Model. In the environment of MATLAB/SIMULINK, a simulation model of variable specific heat capacity of three shaft gas turbine was built, which includes compressor, combustion chamber, turbine, volume, rotor and engine controller, which is shown in Figure 6.

3.2. Optimized Scheme of VSV for Marine Gas Turbine. Based on the gas turbine's overall performance, this part of the paper has considered variable-geometry compressor's (0-1) variable dimensions of the gas turbine overall simulation model, aiming at optimizing the gas turbine's economics by taking angles of variable stator vane as the optimized variables. In the process of selecting optimized variables, the adjustable angles of the variable stator vane have been taken as optimized variables to improve the design of stator vane adjustment scheme. The optimization target is the economy of the gas turbine, whose specific measurement index is the fuel consumption rate and efficiency during the operation of the gas turbine. The gas turbine efficiency is defined as the formula below:

$$
\eta=\frac{W_{T}}{G_{f} H_{u}},
$$

where $G_{f}$ is the fuel mass flow; $H_{u}$ is the fuel low calorific value; $W_{T}$ is the turbine power.

At the same time, the surge margin should be considered in the optimization target of the optimization scheme as well, and the surge margin is defined as follows:

$$
\mathrm{SM}=\left[\frac{(\pi / \bar{G})_{s}}{(\pi / \bar{G})_{o}}-1\right] \times 100 \% .
$$

There are 3 stages of variable stator vanes in this paper. Considering the combination number of three optimization variables and the selection rules of optimization variables, this paper adopts the optimization scheme of traverse tree algorithm (Figure 7) to optimize the overall performance of the gas turbine under different conditions.

In the optimization scheme shown in Figure 7, the optimization process of the multistage variable stator vane opening degree combination can be seen by the process of the 
TABLE 2: Optimization results of variable stator blade at each condition.

\begin{tabular}{lccccc}
\hline $\begin{array}{l}\text { Operating } \\
\text { conditions (\%) }\end{array}$ & $\begin{array}{c}\text { Speed of compressor } \\
(\mathrm{r} / \mathrm{min})\end{array}$ & $\begin{array}{c}\text { Outlet pressure of } \\
\text { compressor }(\mathrm{Pa})\end{array}$ & $\begin{array}{c}\text { Adjustment value of } \\
\text { the zero stage }\left(^{\circ}\right)\end{array}$ & $\begin{array}{c}\text { Adjustment value of } \\
\text { the first stage }\left(^{\circ}\right)\end{array}$ & $\begin{array}{c}\text { Adjustment value of } \\
\text { the second stage }\left({ }^{\circ}\right)\end{array}$ \\
\hline 100 & 7395 & 448850 & -8 & -12 & 0 \\
90 & 7227 & 431587 & -10 & -12 & -2 \\
80 & 7087 & 414645 & -14 & -12 & -12 \\
70 & 6950 & 395360 & -18 & -14 & -1 \\
60 & 6712 & 375084 & -18 & -14 & -12 \\
50 & 6468 & 353210 & -18 & -16 & \\
\hline
\end{tabular}

TABLE 3: The system simulation results of two kinds of schemes at high work conditions.

\begin{tabular}{|c|c|c|c|c|}
\hline \multirow{2}{*}{ Parameter } & \multicolumn{2}{|c|}{$100 \%$ conditions } & \multicolumn{2}{|c|}{$70 \%$ conditions } \\
\hline & Original & Optimized & Original & Optimized \\
\hline Air mass flow (kg/s) & 85.2 & 85.54 & 72.86 & 73.83 \\
\hline Fuel flow $(\mathrm{kg} / \mathrm{s})$ & 1.6921 & 1.6866 & 1.2582 & 1.2432 \\
\hline Efficiency & $33.58 \%$ & $33.69 \%$ & $31.61 \%$ & $32.00 \%$ \\
\hline LC surge margin & $38.33 \%$ & $34.03 \%$ & $37.3 \%$ & $36.54 \%$ \\
\hline HC surge margin & $38.02 \%$ & $38.23 \%$ & $41.19 \%$ & $41.76 \%$ \\
\hline
\end{tabular}

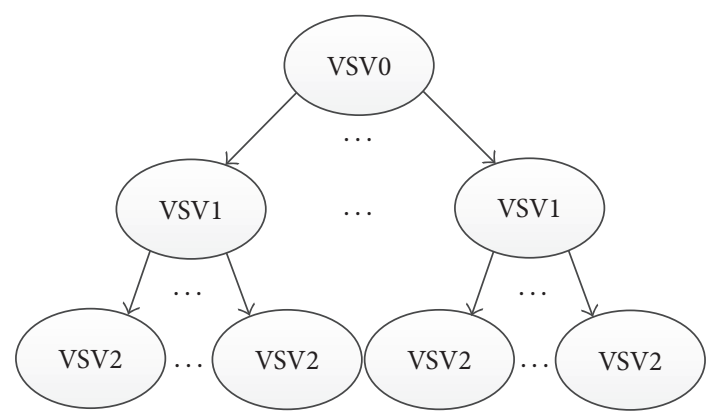

FIgURE 7: The schematic diagram of traverse tree algorithm.

traversing tree. When the zero-stage variable stator vanes take a value within its limits, the first-stage variable stator vanes will take all the opening degree values in its range; at the same time, when the opening degree of the first-stage variable stator vanes is determined, the third-stage variable stator vanes can be selected by traversal as well. And the number of multistage variable stator vanes opening degree combinations in the final optimization scheme is the number of all leaf nodes in the "tree."

Due to the scope of the optimization variables and the limit of selection rules, the total number of all opening degree combinations is still at an acceptable level. At the same time, considering the complexity of the relationship between the optimization variable and the optimization target, it can be found that the optimization problem has obvious unimodality in the optimization process. In each variable stator vane stage, there is always an optimization target corresponding to the opening degree in the range of its opening degree, which is the optimal value, showing a unimodal phenomenon. According to the law, we can greatly reduce the number of variable stator vane opening degree combinations and simplify the optimization process.

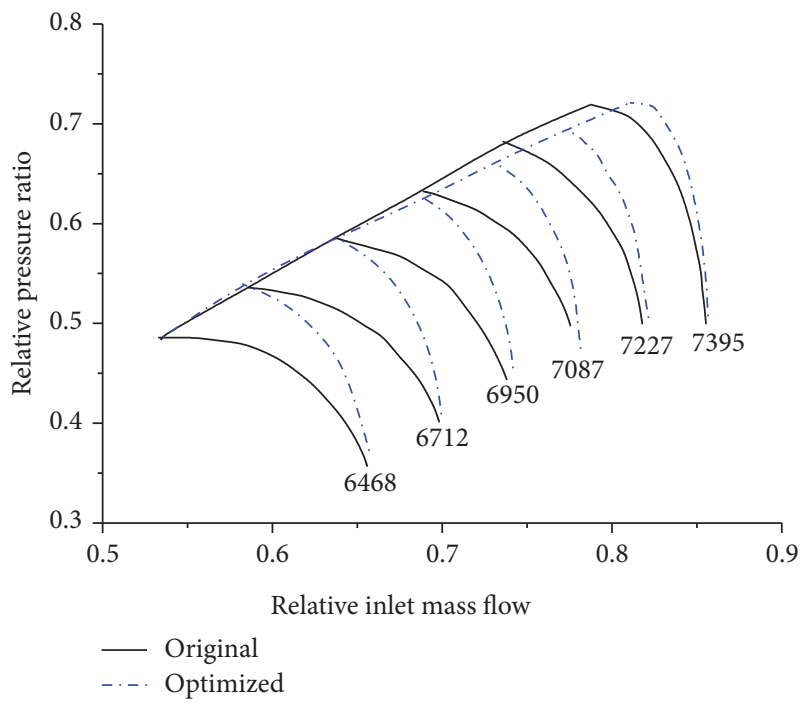

FIgURE 8: Mass flow and pressure ratio.

3.3. Optimization Results and Analysis. The low-pressure compressor variable stator blade adjustable regulation law has been optimized at different off-design points of the gas turbine. Table 2 shows the results of the optimization.

It can be calculated in the low-pressure compressor characteristic curves of each condition by inputting optimized adjustment schemes of variable stator vane into the model, as shown in Figures 8 and 9. It can be seen from Figure 8 that the compressor surge margin that has been optimized seems more gentle compared to the original surge margin. In Figure 9, the efficiency of the low-pressure compressor has significantly improved compared to the original scheme.

The changing curves of gas turbine efficiency and fuel quantity in various conditions by applying the optimized variable stator blade adjustment scheme to the simulation 


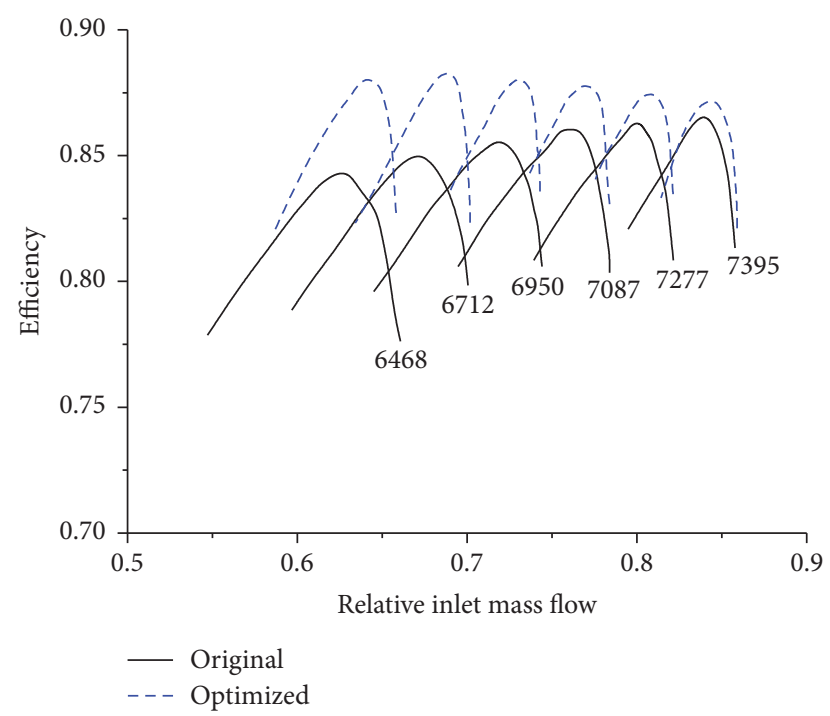

Figure 9: Mass flow and efficiency.

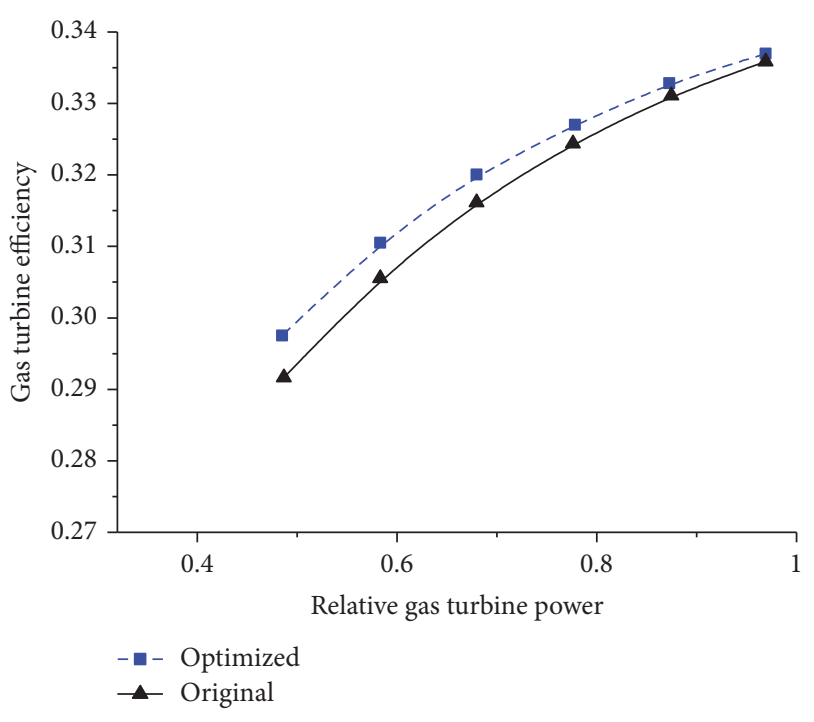

FIgURE 10: The efficiency of the gas turbine.

model are shown in Figures 10-11. It can be seen from Figures 10 and 11 that the overall efficiency was significantly higher than the original regulation scheme above $50 \%$ conditions, and the fuel mass flows are lower than the original scheme.

3.4. Results and Analysis of the Steady-State Performance of Marine Gas Turbine. The steady-state calculation of a threeshaft gas turbine for a certain type of ship's power generation is carried out, which is under the original adjustable stator blade adjustment scheme, the optimal regulation scheme, and the no adjustment scheme. The comparison results of the various parameters of the gas turbine engine used in the marine power generation are shown in Figures 12-15.

Specific analysis of simulation results is as follows.

From Figures 12-13, when the adjustable stator blade maintains the design position, the low-pressure rotor speed is

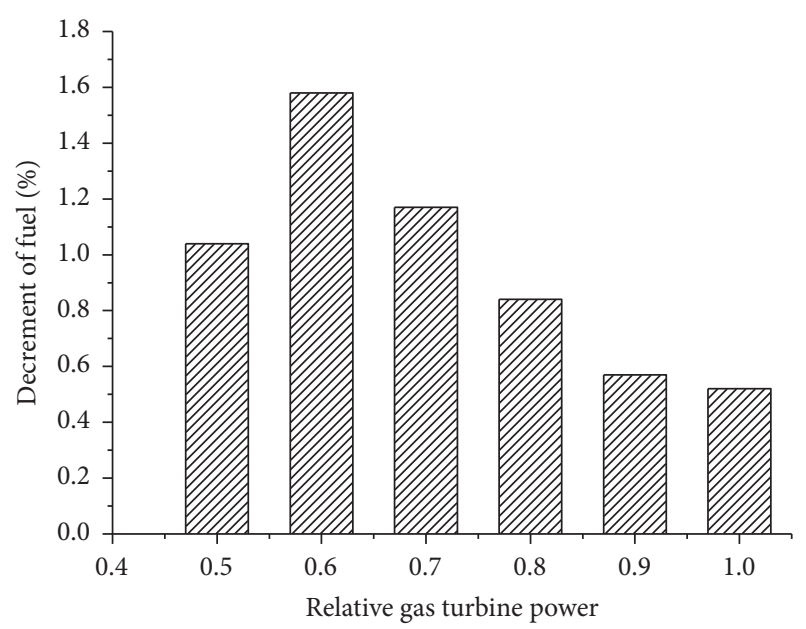

FIGURE 11: The fuel flow of the gas turbine.

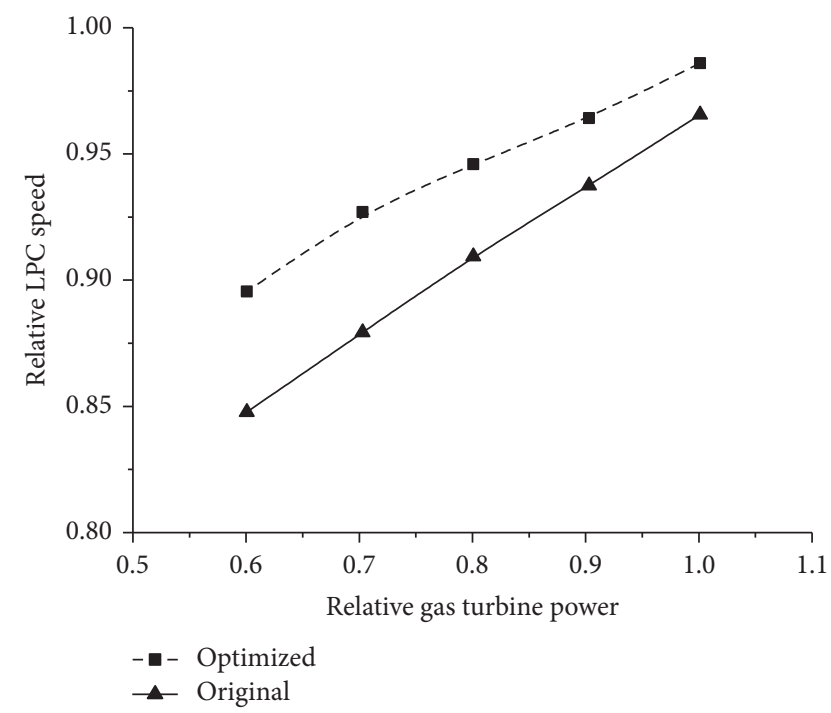

FIGURE 12: The speed of the low-pressure rotor.

low and the high-pressure rotor speed is higher in each steady state. At the same time, compared to the original adjustment scheme, the optimized stator blade adjustment scheme is more different than the original method. It can reduce the consumption of fuel flow and improve the economic performance of the gas turbine by adjusting the adjustable stator blade, which is shown in Figure 14. In Figure 15, in the use of adjustable stationary blade adjustment mode, lowpressure compressor surge margin under different operating conditions is at a safe level. Through the adjustment of the adjustable stationary blades, the working condition of the compressor is in good coordination and it can enhance the stability of the gas turbine and scope of work of the compressor. As can be seen from Figure 16, the efficiency of the whole machine is greatly improved by adjusting the adjustable stator blade in each steady state of the combustion engine. 


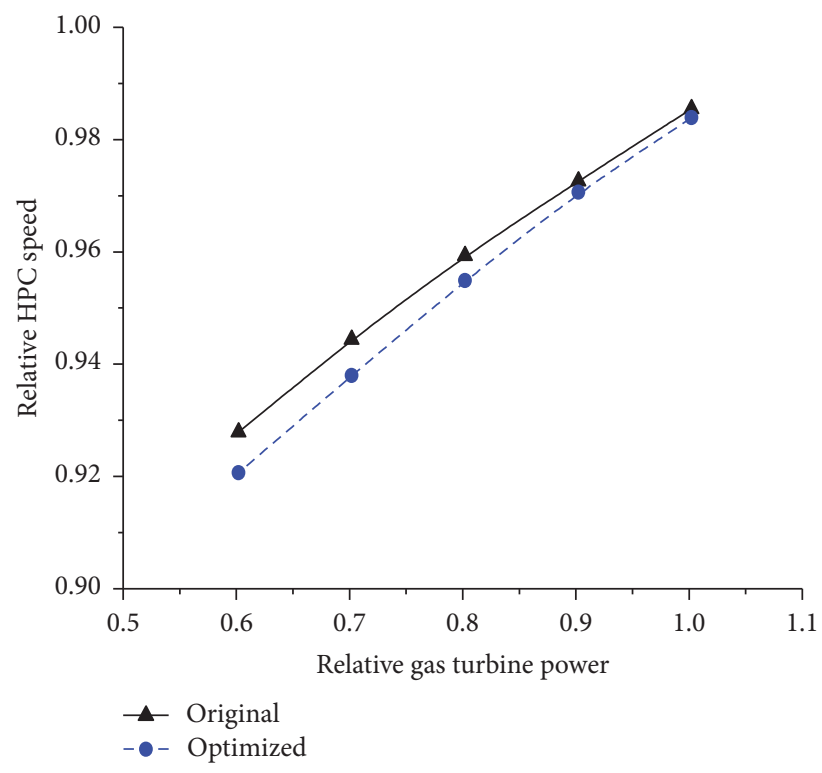

FIgURE 13: The speed of the high-pressure rotor.

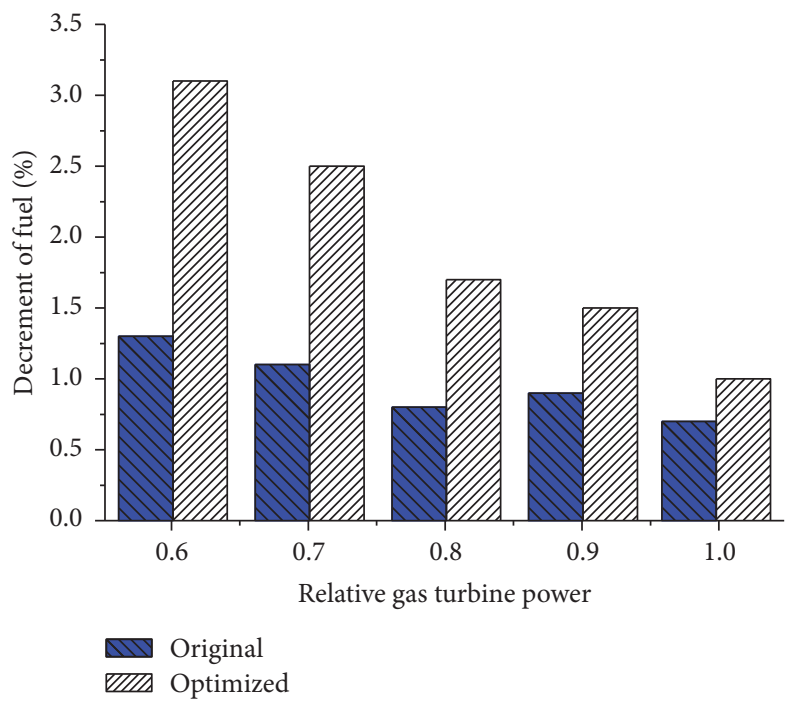

Figure 14: The fuel flow of the gas turbine.

\section{Conclusions}

In consideration of the characteristics of the variablegeometry compressor, a characteristic calculation program of a one-dimensional compressor was used in the $0 \mathrm{D}$ simulation model of the gas turbine through scaling simulation. In the end, the simulation model of the gas turbine with variable dimension was built. The three-stage VSV of the low-pressure compressor is used as the optimization variable, the economy of the gas turbine under different conditions is used as the optimization goal, and the best adjustment angles of the three-stage VSV were got under different working conditions. From the optimization results, we can find that the optimized control scheme can improve the efficiency of the gas turbine

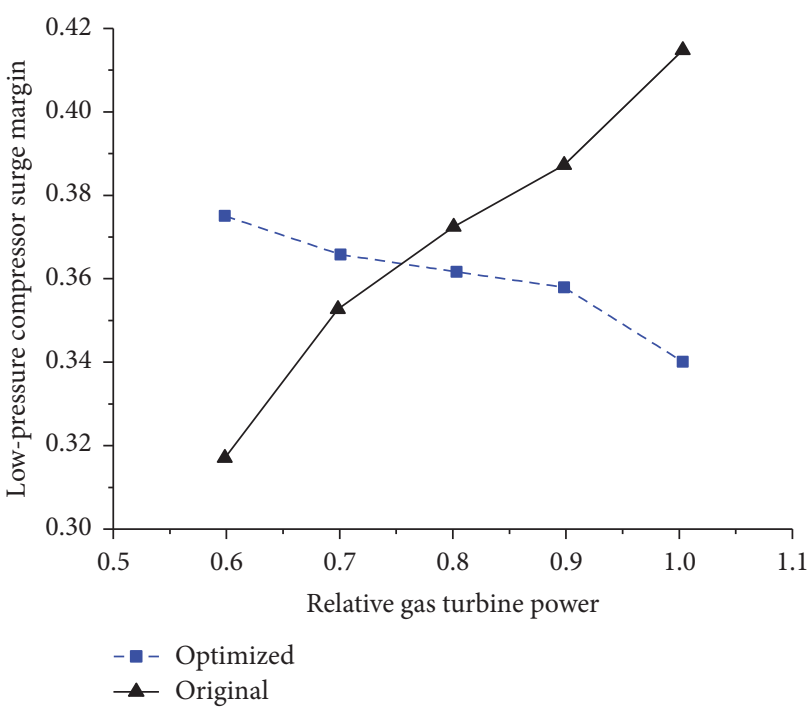

FIGURE 15: The surge margin of the low-pressure compressor.

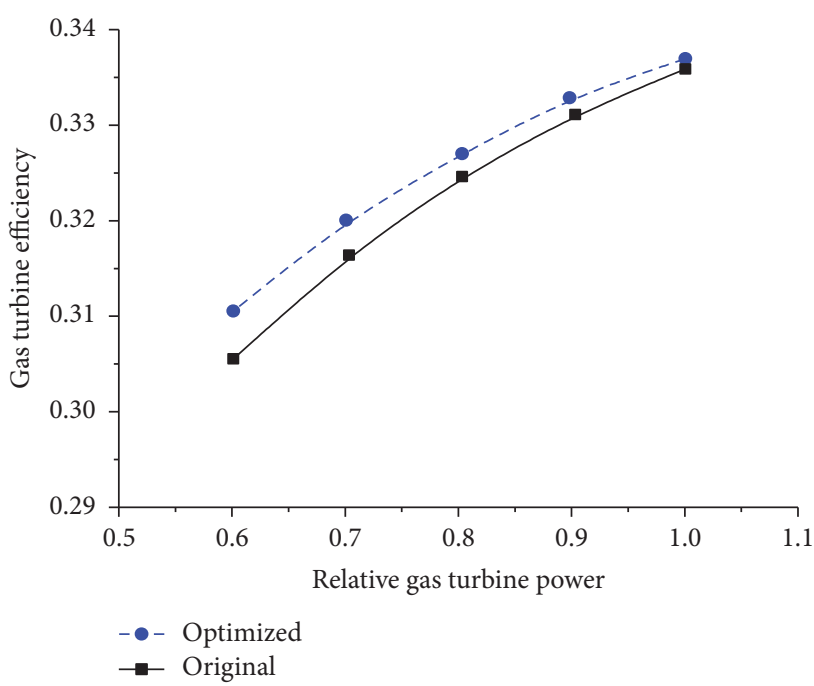

FIGURE 16: The efficiency of the gas turbine.

and reduce fuel consumption. Although the surge margin is less than the original program's surge margin under high working conditions, in the low and medium conditions, the optimization scheme has more advantages. Through the reasonable adjustable stationary blades adjustment scheme, we can improve the gas turbine compressor surge margin under the working condition of low and medium. Meanwhile, we can expand the operating range of the compressor, and the gas turbine can get a better operation state. The operating performance of the gas turbine under different operating conditions is improved. It is believed that the reasonable adjustment scheme of the stator has a positive effect on the overall performance of the gas turbine. 


\section{Notation}

\section{Acronyms}

VSV: Variable stator vane

LPC: Low-pressure compressor

HPC: High-pressure compressor.

\section{Variables}

h: Enthalpy

T: Temperature

$N$ : Power

$G$ : Mass flow

$P$ : Pressure

$C_{p}$ : Specific heat at constant pressure

$R_{g}$ : Gas constant

$H_{u}$ : Low calorific value of fuel

$V$ : Volume

$J: \quad$ Rotor inertia

$M$ : Torque

$W$ : Power.

\section{Greek Symbols}

$\pi$ : Pressure ratio

$\eta$ : Efficiency

$\kappa$ : Index adiabatic of combustion chamber

$\omega$ : Angular speed.

\author{
Subscripts \\ in: Inlet of compressor \\ out: Outlet of compressor \\ c: Compressor \\ $s:$ Isentropy \\ b: Combustion \\ in: Inlet \\ out: Outlet \\ $t$ : Turbine \\ $f$ : Fuel \\ L: Load.
}

\section{Conflicts of Interest}

The authors declare that they have no conflicts of interest.

\section{Acknowledgments}

The present work is supported by the Fundamental Research Funds for the Central Universities of China (no. HEUCFM170301).

\section{References}

[1] J. Zhang, Model Research of Engine Performance Based on Level Superposition of Compressor, Beihang University, Beijing, China, 2010.
[2] W. Deng, Research on Simulation Technology of Gas Turbine, Nanjing University of Aeronautics and Astronautics, Nanjing, China, 2012.

[3] D. P. Petters and J. L. Felder, "Engine system performance of pulse detonation concepts using the NPSS program," in Proceedings of the 38th AIAA/ASME/SAE/ASEE Joint Propulsion Conference and Exhibit, July 2002.

[4] R. Sampath, R. Plybon, C. Meyers, R. Irani, and M. Balasubramaniam, "High fidelity system simulation of aerospace vehicles using NPSS," in Proceedings of the 42nd AIAA Aerospace Sciences Meeting and Exhibit, AIAA, Reno, Nevada.

[5] M. G. Turner, R. Ryder, J. A. Reed, and J. P. Veres, "Multi-fidelity simulation of a turbofan engine with results zoomed into minimaps for a Zero-D cycle simulation," in Proceedings of the 2004 ASME Turbo Expo, pp. 219-230, ASME, Vienna, Austria, June 2004.

[6] N. D. Semkin, A. V. Piyakov, K. E. Voronov, N. L. Bogoyavlenskii, and D. V. Goryunov, "A linear accelerator for simulating micrometeorites," Instruments and Experimental Techniques, vol. 50, no. 2, pp. 275-281, 2007.

[7] M. T. Schobeiri, "Active aerodynamic control of multi-stage axial compressor instability and surge by dynamically adjusting the stator blades," in Proceedings of the ASME Turbo Expo 2001: Power for Land, Sea, and Air, GT 2001, ASME, New Orleans, La, USA, June 2001.

[8] V. Cyrus, "Aerodynamic performance of an axial compressor stage with variable rotor blades and variable inlet guide vanes," in Proceedings of the ASME International Gas Turbine and Aeroengine Congress and Exhibition, GT 1998, ASME, Stockholm, Sweden, June 1998.

[9] T. R. Camp and I. J. Day, "A study of spike and modal stall phenomena in a low-speed axial compressor," Journal of Turbomachinery, vol. 120, no. 3, pp. 393-401, 1998.

[10] J. E. Roy-Aikins, "Considerations for the use of variable geometry in gas turbines," in Proceedings of the ASME International Gas Turbine and Aeroengine Congress and Exposition, ASME, Brussels, Belgium.

[11] C. Celis, P. D. M. R. Pinto, R. S. Barbosa, and S. B. Ferreira, "Modeling of variable inlet guide vanes affects on a one shaft industrial gas turbine used in a combined cycle application," in Proceedings of the ASME Turbo Expo, pp. 1-6, ASME, Berlin, Germany, June 2008.

[12] A. Wiedermann, D. Frank, U. Orth, and M. Beukenberg, "Computational and experimental analysis of an industrial gas turbine compressor," in Proceedings of the ASME Turbo Expo: Turbine Technical Conference and Exposition, GT2011, pp. 319329, ASME, Vancouver, British Columbia, Canada, June 2011.

[13] Y. Hu, Study of DSP Control Technology for Inlet Guide Vane/Stator in Multi-stage Axial Compressor [Dissertation, thesis], School of Chinese Academt of Sciences, China, 2009.

[14] Y. Hu and C. Nie, "Exploration of variable working condition of guide vane/stator vane/the rotational alignment in axial compressor," Chinese Science:Science and Technology, vol. 7, pp. 765-771, 2010.

[15] J. F. Klapproth, M. L. Miller, and D. E. Parker, "Aerodynamic development and performance of the CF6-6/LM2500 compressor," AIAA, 1979, 79-7030.

[16] A. R. Wadia, D. P. Wolf, and F. G. Haaser, "Aerodynamic design and testing of an axial flow compressor with pressure ratio of 23.3:1 for the LM2500+ gas turbine," Journal of Turbomachinery, vol. 124, no. 3, pp. 331-340, 2002. 
[17] W. Hu, M. Kai, and S. Na, "Optimization of variable geoemetry and performance constrains of multistage axial compressor," Aircraft Engine, vol. 38, article 15706, pp. 11-15, 2012.

[18] W. Hu, "Multi objective optimization of multi stage axial compressor with variable geometry," Journal of Engineering Thermal Physics, vol. 3512, pp. 2363-2366, 2014.

[19] W. Hu and S. Na, "Optimization analysis of multi blade row adjustment and expansion of multi stage axial compressor," Mechanics and Practice, vol. 3202, pp. 26-31, 2010.

[20] W. Hu and S. Na, "Sun Na.Research on variable geometry optimization method of multi stage axial compressor," Journal of Aerospace Power, vol. 2411, pp. 2558-2563, 2009.

[21] J. Zhang and M. Ren, "Experimental study on the influence of static blade angle on compressor performance," Journal of Aerospace Power, vol. 1, pp. 27-30, 2000. 


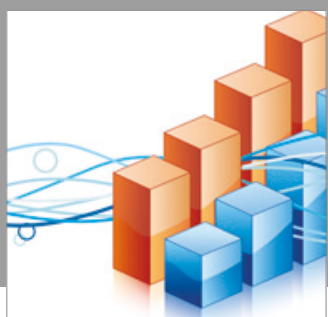

Advances in

Operations Research

vatersals

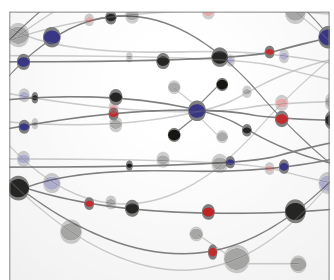

\section{The Scientific} World Journal
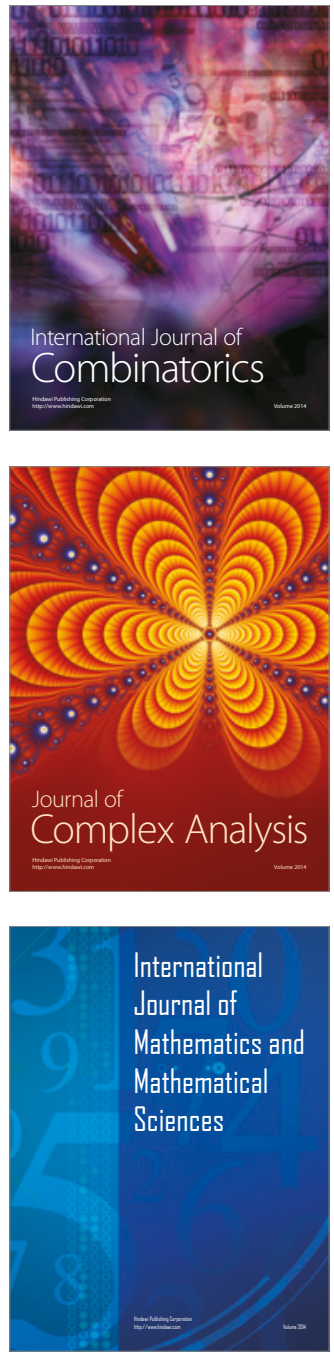
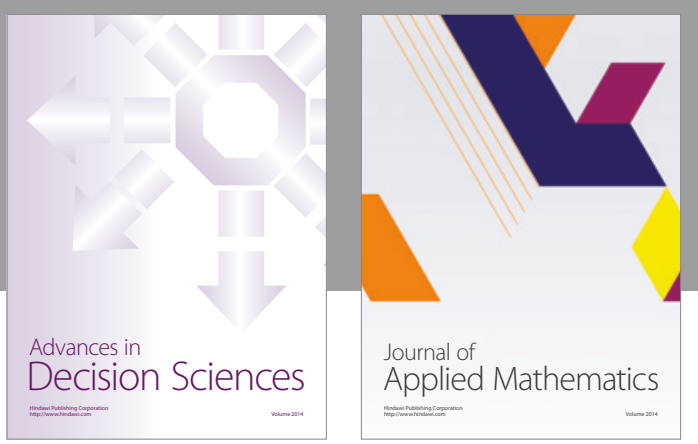

Algebra

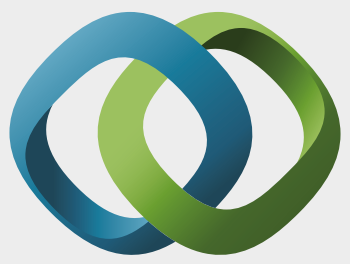

\section{Hindawi}

Submit your manuscripts at

https://www.hindawi.com
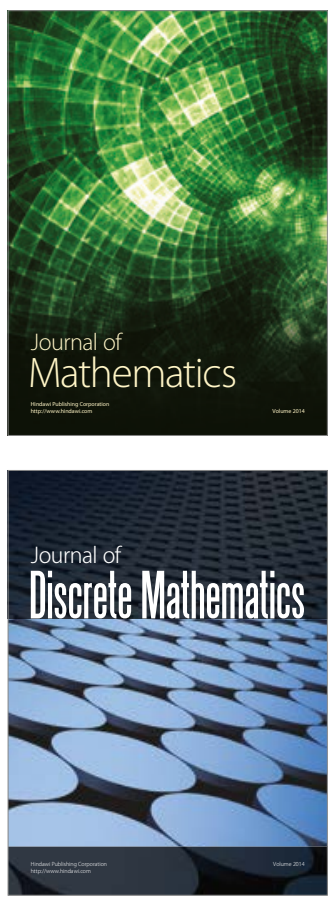

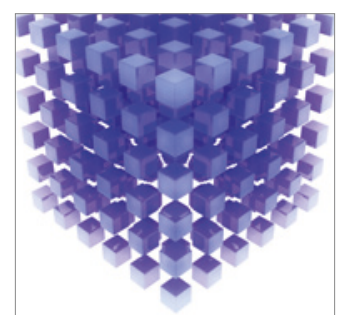

Mathematical Problems in Engineering
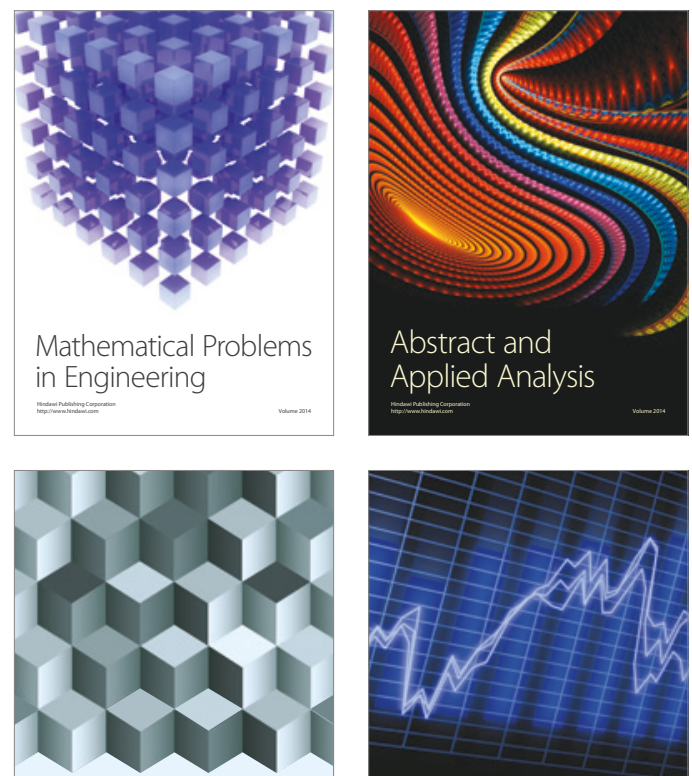

Journal of

Function Spaces

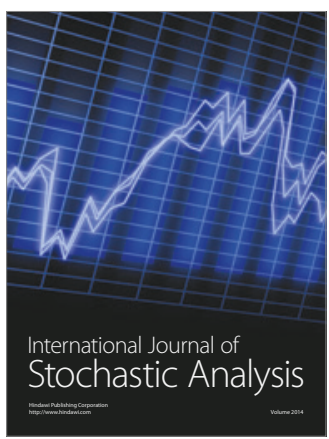

Probability and Statistics
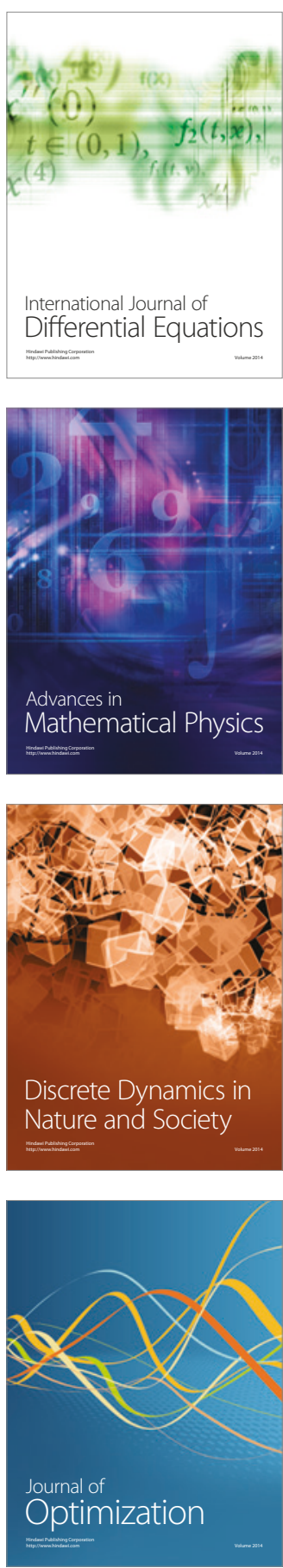